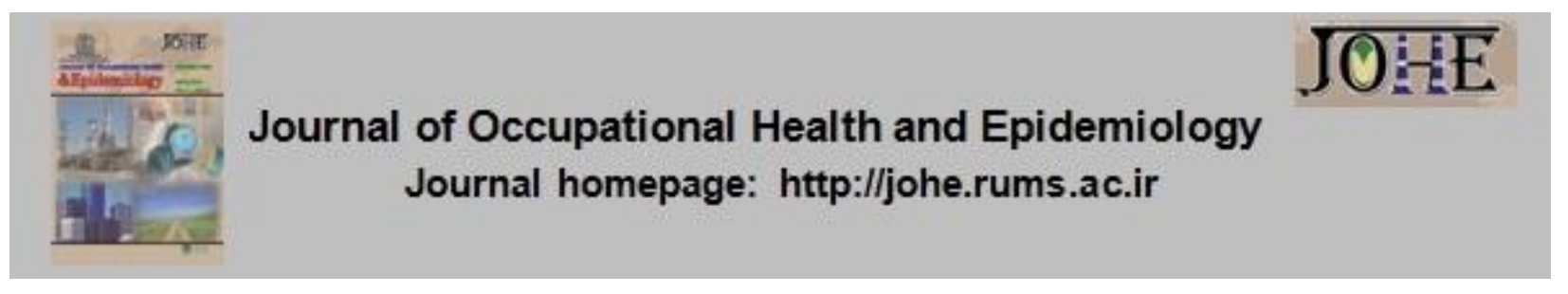

\title{
Pathology and Epidemiology of Plagiarism (1)
}

\author{
Reza Vazirinejad ${ }^{1}$ \\ 1- Professor in Epidemiology, Social Determinants of Health Research Center, Rafsanjan University of Medical \\ Sciences, Rafsanjan, Iran.
}

These days we have been hearing the news from different academic organizations, including medical universities and health research groups, that unfortunately some people working in the scientific centers fall in different sorts of plagiarism traps. It is even more terrible knowing that this is an iceberg shape problem (1). Of course this is not acceptable even though it might happen unconsciously. Mistakes due to the shortage of knowledge in the field of research ethics could be resolved by conducting educational programs in the different branches of the research. What is critically important and must be controlled as soon as possible is the plagiarism which happens consciously. The first step for controlling these types of plagiarism is working on its pathology as well as its epidemiology. In the other word, we need to know "why an academic person decides to commit plagiarism?" Many reasons could be listed by people, but one of them seems to be very important. My experience of working in a medical school for about 25 years and my contacts with my colleagues in different medical universities shows that our policies in the medical universities have deteriorated this unfortunate problem. In our medical universities we have forgotten that the ultimate target of research and publication is creation of new science which help human health. It seems like we have not attempted to teach our young students that this is the main reason for conducting research or whatsoever. Let me correct myself, may be the way we act with our research findings has misled our younger researchers!! We all accept that we would like to make a product from our findings (such as changing a behavior). But, what is this product?! Or what does "product" means? Martisiute et al presented a list of definitions for the "product" in 2010 (2). Regarding these definitions presented for "product", all of them refer to a concept for "satisfying a need". Now, what is the "need"? to reply, first we should say "whose need?" in other words, we should clarify that who should benefit from the research product? People or the researcher?! This is the key question. If we bear in mind that only the researcher (me) should have the benefit from the research, therefore in many cases, the ultimate target would be the PAPER! Because the researcher knows that it is not easy to sell the results of his health research to a customer in particular when layman people are the main customers!!. Publishing papers help the researcher to improve his academic position, for instance from assistant professor to an associate professor to a 
full professor. Or, helping him become a famous person in his field in the country or even in the world which is of course very tempting. Therefore, publishing a paper could become an ultimate target even if it is not honestly written, specially, when there is no method to help the journalists to detect many of the worse types of plagiarism such as data fabrication (3). It is a sad scenario, but who should be to blame?!

Medical universities have their own policies for improving both their staff position (people who work as researcher or lecturer) and the university position. It would be fine as long as they encourage their staff to publish papers, however, it would become a risk for plagiarism when it becomes an obligation. It would be even worse when there is no control or supervision. There might be this need in the near future to ask the universities or the research authorities to confirm research manuscripts before publication. There is still a long way to go for ethics considerations in the research worldwide.

\section{References}

1- Sovacool BK. Exploring scientific misconduct: isolated individuals, impure institutions, or an inevitable idiom of modern science? J Bioeth Inq 2008; 5:27182.

2- Martisiute S, Vilutyte G, Grundey D. Product or brand? how interrelationship between customer satisfaction and customer loyalty work. European Journal of Interdisciplinary Studies 2010; 2(1):5-15.

3- Fanelli D. How many scientists fabricate and falsify research? a systematic review and meta-analysis of survey data. PLoS ONE 2009; 4(5):e5738. 